Check for updates

Cite this: RSC Adv., 2017, 7, 48161

\title{
A facile method to prepare energetic materials (EMs) $\dagger$
}

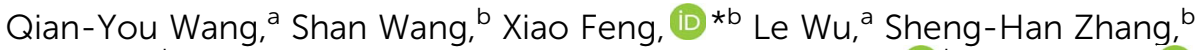 \\ Nan Ding, ${ }^{b}$ Wen-Chao Tong, ${ }^{a}$ Ming-Rui Zhou, ${ }^{c}$ Bo Wang (DD ${ }^{b}$ and Li Yang (DD *a
}

Two powerful yet safe energetic materials (EMs) have been synthesized with high yield via a facile method. We used low-cost industrial products as starting materials and water as a solvent rather than organic solvents without generating harmful by-products during the two-step synthetic procedure. Purification of the target materials could be obtained through a simple separation process with low energy consumption. Moreover, the thermal stability, insensitivity, and explosive performance of these two EMs are better than that of commonly used energetic materials such as TNT and TATB (2,4,6-triamino-1,3,5trinitrobenzene).

Received 23rd July 2017

Accepted 7th October 2017

DOI: $10.1039 / \mathrm{c} 7 \mathrm{ra0} 8115 \mathrm{~d}$

rsc.li/rsc-advances

purification; reaction procedures are usually complicated yet the yields are often low.

In this research, we reported a facile two-step synthetic strategy to prepare two nitrogen-rich energetic salts (EM-1 and EM-2) with high yield and purity under mild conditions by using low-cost industrial products as raw materials through a hydrothermal approach without the production of environmentally harmful by-products. Comprehensive studies of the reaction conditions and the effects of the substituent groups in the starting materials allowed for the synthesis of energetic salts. Their crystal structures, thermal decomposition behaviors, nonisothermal kinetics and sensitivities and calculated their detonation velocities and detonation pressures were investigated. Both of these salts possess high enthalpy of formation and good explosive performance with high thermal stability, insensitivity towards impact, friction, and electrostatic discharge. This strategy presents an alternative synthetic procedure that suitable for industrial preparation and applications.

Based on the following considerations, we designed and synthesized 1,2-bis(hydrazinocarbonyl)hydrazine (BHCH) as the cation component of the energetic salts through the reaction of commercial available dialkyl azodicarboxylates and hydrazine hydrate in high yield. Firstly, $\mathrm{BHCH}$ has high nitrogen content and multiple energetic $\mathrm{N}-\mathrm{N}$ and $\mathrm{N}-\mathrm{C}$ bonds, which give rise to high enthalpy of formation and good explosive performance. Secondly, the carbonyl group and hydrazine group of BHCH can form hydrogen bonds with other energetic anions, which may improve the thermal stability and safety of the energetic materials. ${ }^{23-25}$ Moreover, the flexible chain structure of $\mathrm{BHCH}$ is beneficial for the formation of more hydrogen bonds compared to normal N-heterocyclic compounds with rigid structure. Thirdly, it is worth noting that the starting materials, dialkyl azodicarboxylates, are cost effective and widely used in industry as foaming agents and plasticizers.
${ }^{a}$ State Key Laboratory of Explosion Science and Technology, Beijing Institute of Technology, Beijing 100081, P. R. China. E-mail: yanglibit@bit.edu.cn

${ }^{b}$ Ministry of Education of China, School of Chemistry, Beijing Institute of Technology, 5 South Zhongguancun Street, Beijing 100081, P. R. China. E-mail: fengxiao86@bit.edu.cn 'Logistics Center, China Academy of Launch Vehicle Technology, Beijing 100076, P. R. China

$\dagger$ Electronic supplementary information (ESI) available. CCDC 1483054-1483056. For ESI and crystallographic data in CIF or other electronic format see DOI: $10.1039 / \mathrm{c} 7 \mathrm{ra} 08115 \mathrm{~d}$ 
Fourthly, the by-products of the reaction are $\mathrm{N}_{2}, \mathrm{H}_{2} \mathrm{O}$ and alcohols. Finally, the $\mathrm{BHCH}$ is able to react with picric acid (PA) or 2,4,6-trinitroresorcinol (TNR) to obtain halogen-free and metal-free $\mathrm{BHCH}$-containing EMs in water at $60{ }^{\circ} \mathrm{C}$ minimizing pollution (Scheme 1).

Initially, we focused our efforts on optimizing the reaction conditions for the synthesis of $\mathrm{BHCH}$. Five industrially abundant and inexpensive dialkyl azodicarboxylates, dimethyl azodicarboxylate (DMAD), diethyl azodicarboxylate (DEAD), diisopropyl azodicarboxylate (DIAD), di-tert-butyl azodicarboxylate (DTAD) and dibenzyl azodicarboxylate (DBAD), were chosen to react with $60 \%$ hydrazine hydrate solution that acts as both nucleophilic reagent and reducing agent in a $1: 3$ ratio. The reaction was carried out at $70{ }^{\circ} \mathrm{C}$ temperature overnight. Pure $\mathrm{BHCH}$ could be obtained via simple precipitating in ethanol without the need of recrystallization or column purification. The yields could reach 43\%, 52\%, 34\%, 31\%, and 39\% for DMAD, DEAD, DIAD, DTAD, and DBAD as starting materials, respectively. Single-crystal X-ray analysis (SXRD), ${ }^{1} \mathrm{H}-\mathrm{NMR}$, IR and MS spectra confirmed the structure and purity of the resultant product.

We chose DEAD as starting material and further investigated the effects of the ratio of the starting materials and reaction temperatures to optimize its reaction conditions. The yields were improved by increasing the amount of hydrazine hydrate and hit a plateau at a ratio of $1: 5$ (Fig. 1c). It reached maximum yield of $92 \%$ with a reaction temperature of $70{ }^{\circ} \mathrm{C}$ (Fig. 1d), further increasing the temperature would lead to cyclization side reactions and formation of by-products.

After optimizing the reaction conditions for $\mathrm{BHCH}$, we prepared energetic salts by reacting $\mathrm{BHCH}$ with PA or TNR in water at $60{ }^{\circ} \mathrm{C}$ for $1 \mathrm{~h}$. Then, the mixtures were cooled to room temperature, and EM-1 (PA ${ }^{-}$as counter ion) or EM-2 (TNR ${ }^{-}$as counter ion) were precipitated out of solution and recovered through filtration with up to $87 \%$ and $82 \%$ yield, respectively. The structures and purities of EM-1 and EM- 2 were confirmed by IR, elemental analyses and SXRD. The synthesis of these two EMs undergo an acid-base reaction in water avoiding both the use of organic solvents and the formation of toxic by-products to produce two metal-free and halogen-free materials. Compared with commonly used decomposition reaction for the syntheses of energetic salts, the acid-base reaction is more eco-friendly and simple.

SXRD analyses showed that EM-1 is composed of the univalent cation of $\mathrm{BHCH}$ and $\mathrm{PA}^{-}$with the ratio of $1: 1$ and

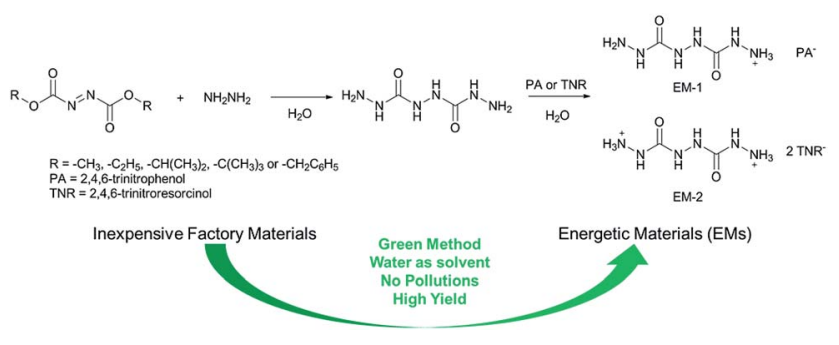

Scheme 1 Synthetic strategies to prepare EM-1 and EM-2.

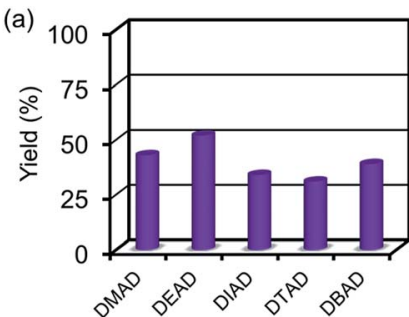

(b)
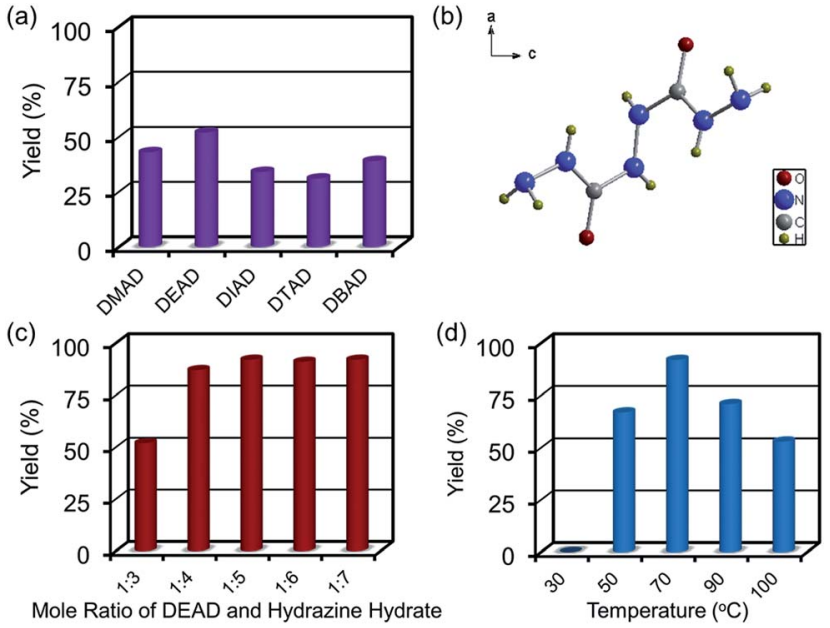

Fig. 1 (a) Yields of $\mathrm{BHCH}$ using different starting materials; (b) the structure of $\mathrm{BHCH}$; (c) yields of $\mathrm{BHCH}$ with different mole ratios of $\mathrm{DEAD}$ and hydrazine hydrate; (d) yields of $\mathrm{BHCH}$ with different reaction temperatures.

EM-2 is composed of the divalent cation of $\mathrm{BHCH}$ and $\mathrm{TNR}^{-}$ with the ratio of $1: 2$. As shown in Table S1 (ESI $\dagger$ ), these two EM crystals belong to the monoclinic system with space group $P 2(1) / c$. The energetic $\mathrm{N}-\mathrm{N}$ bond lengths in the EMs range from $1.378(4)$ to $1.421(4) \AA$. Due to intramolecular hydrogen bonding and distortion of $\mathrm{BHCH}$, the $\mathrm{N}-\mathrm{N}$ single bonds between carbon of EM-1 (1.3812 $\AA$ ) and EM-2 (1.378 $\AA$ ) are much shorter than normal N-N single bonds $(1.454 \AA)$ and even shorter than $\mathrm{N}=\mathrm{N}$ double bonds $(1.245 \AA)$. The energetic $\mathrm{N}-\mathrm{C}$ bond lengths in the EMs range from 1.348(4) to 1.467(2) A. As the different group connected to $\mathrm{N}-\mathrm{C}$ bond, the $\mathrm{N}-\mathrm{C}$ bond connected to hydrazine group (1.424 to $1.467 \AA$ ) are longer than $\mathrm{N}-\mathrm{C}$ bond connected to nitro group (1.348 to $1.385 \AA$ ). There exists significant hydrogen bonding between ion and $\pi-\pi$ action between the benzene rings, which may contribute to their densities and stabilities. For example, EM-1 has three types of hydrogen bonds, which are an intramolecular hydrogen bond of $\mathrm{BHCH}(\mathrm{N} 2-\mathrm{H} 2 \cdots \mathrm{O} 2)$, an intermolecular hydrogen bond of $\mathrm{BHCH}(\mathrm{N} 5-\mathrm{H} 5 \cdots \mathrm{O} 2)$ and an intermolecular hydrogen bond between $\mathrm{BHCH}^{+}$and $\mathrm{PA}^{-}$ (N1-H1A …O3) (Fig. 2).

Thermal decomposition temperature of explosives is a crucial parameter in terms of performance. ${ }^{26}$ The thermal behaviors of EM-1 and EM-2 were investigated by differential scanning calorimetry (DSC) measurements with a linear heating rate of $5,10,15,20{ }^{\circ} \mathrm{C} \mathrm{min}^{-1}$ (Fig. 3). At the heating rate is $5{ }^{\circ} \mathrm{C} \min ^{-1}$, the DSC curve of EM-1 has an endothermic peak at 199.11 ${ }^{\circ} \mathrm{C}$ and an exothermic peak at $211.05{ }^{\circ} \mathrm{C}$, corresponding to the melting process and the energy release process, respectively. EM-2 demonstrated one exothermic processes at $215.51{ }^{\circ} \mathrm{C}$ under the same heating rate, revealing its capability in heat generating. Typically, energetic materials with higher than $200{ }^{\circ} \mathrm{C}$ decomposition temperature imply good thermal stability.

Apparent activation energies $\left(E_{\mathrm{a}}\right)$ can be used to estimate the rate constants of the initial thermal decomposition process. We utilized both Kissinger's method and Ozawa's method to 

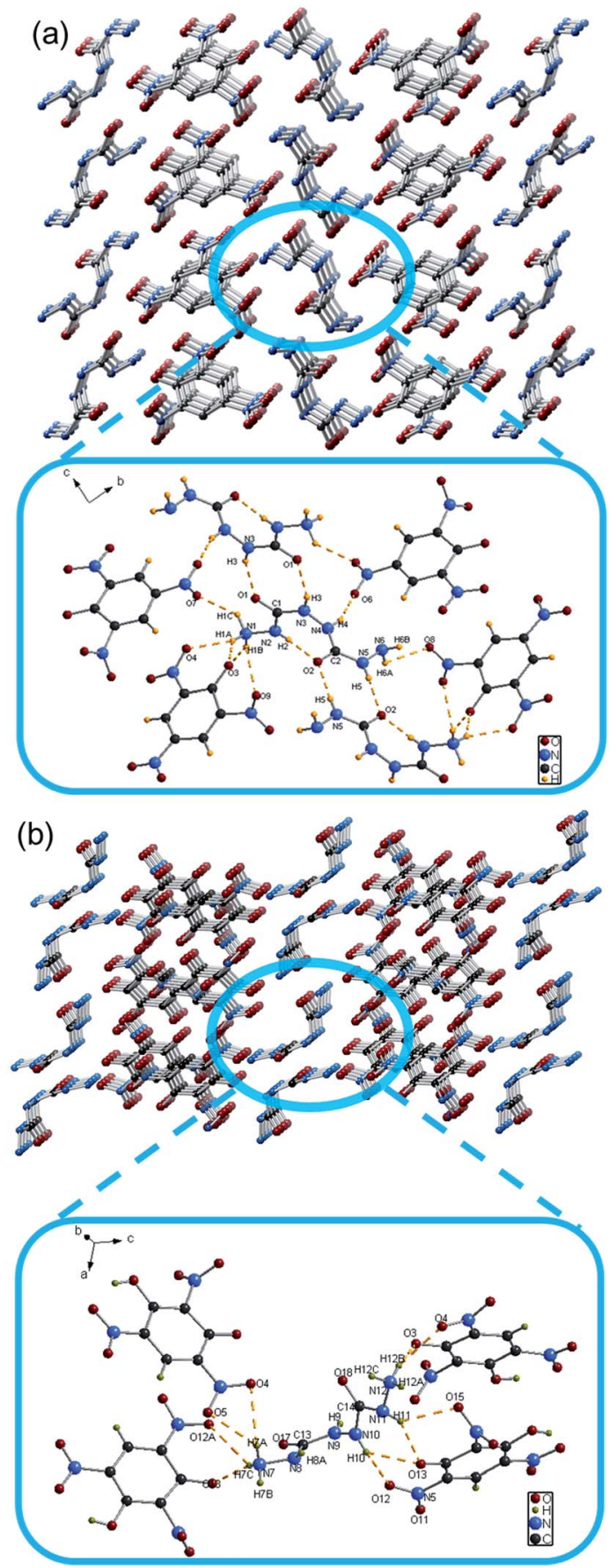

Fig. 2 (a) Packing diagram of EM-1 and hydrogen bonds of EM-1 in the crystal structure; (b) packing diagram of EM-2 and hydrogen bonds of $\mathrm{EM}-2$ in the crystal structure.

calculate the activation energies of these two EMs based on the following equations, ${ }^{27-29}$

Kissinger's method

$$
\frac{d \ln \left(\beta / T_{\mathrm{p}}{ }^{2}\right)}{d\left(1 / T_{\mathrm{p}}\right)}=-\frac{E_{\mathrm{a}}}{R}
$$

(a)
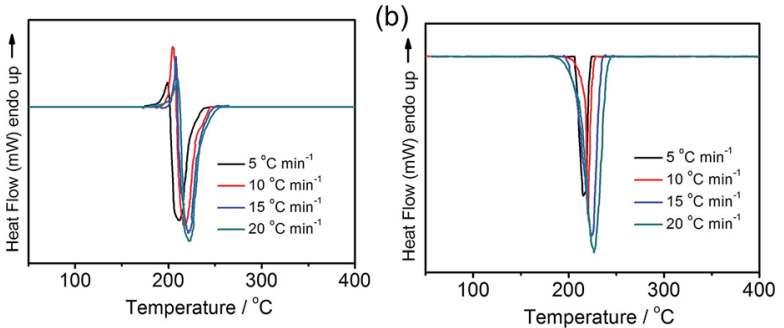

Fig. 3 ( $a$ and b) DSC curves of (a) EM-1 and (b) EM-2 at heating rates of $5,10,15$ and $20{ }^{\circ} \mathrm{C} \mathrm{min}^{-1}$.

Ozawa's method

$$
\log \beta+\frac{0.4567 E_{\mathrm{a}}}{R T_{\mathrm{p}}}=C
$$

where $\beta$ is the linear heating rate, ${ }^{\circ} \mathrm{C} \min ^{-1} ; T_{\mathrm{p}}$ is the peak temperature, ${ }^{\circ} \mathrm{C} ; R$ is the gas constant, $8.314 \mathrm{~J} \mathrm{~mol}^{-1} \mathrm{~K}^{-1} ; C$ is a constant.

According to the exothermic peak temperatures determined at four different heating rates of $5,10,15$ and $25{ }^{\circ} \mathrm{C} \mathrm{min}^{-1}$, the thermo-kinetic parameters of exothermal processes for EM-1 and EM-2 are calculated and shown in Table 1, including the apparent activation energies $E_{\mathrm{O}}$ and $E_{\mathrm{K}}$, pre-exponential factor $A_{\mathrm{K}}$ and linear correlation coefficients $R_{\mathrm{K}}$ and $R_{\mathrm{O}}$. The $E_{\mathrm{a}}$ values of both EM-1 $\left(E_{\mathrm{K}}, 225.7 \mathrm{~kJ} \mathrm{~mol}^{-1} ; E_{\mathrm{O}}, 222.4 \mathrm{~kJ} \mathrm{~mol}^{-1}\right)$ and EM-2 $\left(E_{\mathrm{K}}, 240.7 \mathrm{~kJ} \mathrm{~mol}^{-1} ; E_{\mathrm{O}}, 236.7 \mathrm{~kJ} \mathrm{~mol}^{-1}\right)$ are much higher than RDX $\left(144 \mathrm{~kJ} \mathrm{~mol}^{-1}\right)$.

The safety of these EMs to mechanical stimulation, including impact, friction and electrostatic discharge, were tested according to the corresponding standard methods and corresponding data are summarized in Table 2. The impact sensitivities (IS) of EM-1 and EM-2 are higher than $40 \mathrm{~J}$, indicating that the compounds are insensitive to the impact. These IS values are lower than that of TNT (15 J) and even lower than 3D energetic metal organic frameworks famous for their insensitivies. ${ }^{31,34}$ No friction sensitivities are observed up to $360 \mathrm{~N}$ for these two EMs, while the value of which for RDX is

Table 1 Peak temperatures of the first main exothermic stage at different heating rates and kinetic parameters for EM-1 and EM-2

\begin{tabular}{llll}
\hline & & EM-1 & EM-2 \\
\hline$T_{\mathrm{p}}\left({ }^{\circ} \mathrm{C}\right)$ & 5 & 211.05 & 215.51 \\
& 10 & 217.32 & 220.32 \\
& 15 & 220.81 & 224.17 \\
& 20 & 222.68 & 226.74 \\
& & & \\
Kissinger's method & & 225.7 & 240.7 \\
$E_{\mathrm{K}}\left[\mathrm{kJ} \mathrm{mol}{ }^{-1}\right]$ & & 22.33 & -0.9972 \\
$\ln A_{\mathrm{K}}$ & -0.998 & \\
$R_{\mathrm{K}}$ & & & \\
& & 222.4 & -0.9974 \\
Ozawa's method $\left._{E_{\mathrm{O}}[\mathrm{kJ} \mathrm{mol}}{ }^{-1}\right]$ & & -0.9981 & \\
$R_{\mathrm{O}}$ & & &
\end{tabular}


Table 2 Properties of EMs with TNT, TATB and RDX

\begin{tabular}{|c|c|c|c|c|c|c|c|c|c|c|}
\hline Salts & $D^{a}$ & $\Delta H_{\mathrm{L}}^{b}$ & $\Delta H_{\mathrm{f}}^{c}$ cation & $\Delta H_{\mathrm{f}}^{d}$ anion & $\Delta H_{\mathrm{f}}^{e}$ & $P^{f}$ & $D^{g}$ & IS $^{h}$ & $\mathrm{FS}^{i}$ & $\mathrm{EDS}^{j}$ \\
\hline EM-1 & 1.817 & 440.3 & 643.2 & -108.5 & 94.4 & $28.5\left(27.2^{k}\right)$ & $8046\left(8124^{l}\right)$ & $>40$ & $>360$ & $>24.75$ \\
\hline EM-2 & 1.719 & 967.0 & 2088.1 & -318.6 & 483.9 & $29.0\left(30.7^{k}\right)$ & $8197\left(8330^{l}\right)$ & $>40$ & $>360$ & $>24.75$ \\
\hline TATB $^{32}$ & 1.93 & - & - & - & -139.7 & 30.5 & 8179 & $30-40$ & - & - \\
\hline $\mathrm{RDX}^{33}$ & 1.82 & - & - & - & 83.8 & 34.9 & 8748 & 7.4 & 120 & 0.15 \\
\hline
\end{tabular}

${ }^{a}$ Densities obtained from X-ray measurements $\left(\mathrm{g} \mathrm{cm}^{-3}\right) \cdot{ }^{b}$ Lattice energy $\left(\mathrm{kJ} \mathrm{mol}^{-1}\right) \cdot{ }^{c}$ Molar enthalpy of the formation of cation $\left(\mathrm{kJ} \mathrm{mol}{ }^{-1}\right) \cdot{ }^{d} \mathrm{Molar}$ enthalpy of the formation of anion $\left(\mathrm{kJ} \mathrm{mol}^{-1}\right) .{ }^{e}$ Molar enthalpy of the formation of salt $\left(\mathrm{kJ} \mathrm{mol}^{-1}\right) .{ }^{f}$ Detonation pressure $(\mathrm{GPa}) .{ }^{g}$ Detonation velocity $\left(\mathrm{m} \mathrm{s}^{-1}\right) .{ }^{h}$ Impact sensitivity (J). ${ }^{i}$ Friction sensitivity (J). ${ }^{j}$ Electrostatic sensitivity (J). ${ }^{k}$ Detonation velocity calculated by Explo 5 (m $\mathrm{s}^{-1}$ ). ${ }^{l}$ Detonation pressure calculated by Explo $5(\mathrm{GPa})$.

$120 \mathrm{~N}$. In addition, the two EMs are insensitive to electrostatic discharge (Table S5 $\dagger$ ), which are safer than TNT, RDX and HMX. The significantly high safety of these two EMs may be attributed to the multiple intramolecular and intermolecular interactions in the stacking structures, including hydrogen bonds, ionic bonds and $\pi-\pi$ interactions as shown in literature. ${ }^{\mathbf{2 4 , 2 5}}$

The thermal stabilities of these EMs were characterized after $48 \mathrm{~h}$ heat treatment at $75{ }^{\circ} \mathrm{C}$. Both EM-1 and EM-2 easily withstood a temperature of $75{ }^{\circ} \mathrm{C}$ after two days. Even higher temperatures of $90{ }^{\circ} \mathrm{C}$ did not lead to decomposition for one week. The results show that both EM-1 and EM-2 have a good thermal stability.

The enthalpy of formation is an important parameter for evaluating the performance of energetic salts, which is directly related to the number of nitrogen-nitrogen bonds in ionic species. The enthalpy of formation of EMs was calculated by quantum chemical calculations (ESI, $\uparrow$ Section 6 ) and the results were summarized in Table 2. Both EM-1 and EM-2 exhibit positive heats of formation. In particular, the value of EM-2 (483.9 $\mathrm{kJ} \mathrm{mol}^{-1}$ ) is much higher than TNT (95.3 $\mathrm{kJ} \mathrm{mol}^{-1}$ ), TATB (-139.7 kJ mol$\left.{ }^{-1}\right)$, RDX (80.0 $\mathrm{kJ} \mathrm{mol}^{-1}$ ) and HMX $\left(104.8 \mathrm{~kJ} \mathrm{~mol}^{-1}\right)$.

Based on the calculated values of the heats of formation and the densities of the EMs, the detonation velocities $(D)$ and detonation pressures $(P)$ were calculated by classic KamletJacobs equations ${ }^{35}$ and Explo 5. As shown in Table 2, the calculated detonation pressures of EM-1 (28.5 GPa by $\mathrm{K}-\mathrm{J}$ equations and 27.2 GPa by Explo 5) and EM-2 (30.3 GPa by K-J equations and $30.7 \mathrm{GPa}$ by Explo 5) are superior to TNT (19.5 GPa). The calculated detonation velocities of EM-1 are $8046 \mathrm{~m} \mathrm{~s}^{-1}$ by K-J equations and $8124 \mathrm{~m} \mathrm{~s}^{-1}$ by Explo 5 and the calculated detonation velocities of EM-2 are $8197 \mathrm{~m} \mathrm{~s}^{-1}$ by K-J equations and $8330 \mathrm{~m} \mathrm{~s}^{-1}$ by Explo 5, all of which outperform TNT (6881 $\mathrm{m} \mathrm{s}^{-1}$ ).

\section{Conclusions}

In conclusion, two energetic materials have been synthesized with high yield and low energy-consumption separation process. The synthetic procedure utilized cost-effective simple chemicals as the starting materials, water as solvent and did not generate any toxic by-products. The two EMs are metal-free and halogen-free and exhibit high thermal stability. The apparent activation energies are much higher than those of the normal explosives such as TNT and RDX. Both EM-1 and EM-2 are insensitive to impact, friction, and electrostatic discharge, which indicates enhanced material safety for practical usage. The heats of formation, calculated detonation velocity and calculated detonation pressures of these two EMs demonstrate that they have high explosive power. This facile strategy offers a versatile method to synthesize safe energetic materials.

\section{Conflicts of interest}

There are no conflicts to declare.

\section{Acknowledgements}

We gratefully acknowledge financial support from: the State Key Laboratory of Explosion Science and Technology (No. YB201617); 973 Program (No. 2013CB834704); Provincial Key Project of China (No. 7131253); the National Natural Science Foundation of China (No. 11672040, 21471018, 21404010, 21490574); 1000 Plan (Youth).

\section{Notes and references}

1 D. M. Badgujar, M. B. Talawar, S. N. Asthana and P. P. Mahulikar, J. Hazard. Mater., 2008, 151, 289-305.

2 A. K. Sikder and N. Sikder, J. Hazard. Mater., 2004, 112, 1-15. 3 X. Liu, W. Gao, P. Sun, Z. Su, S. Chen, Q. Wei, G. Xie and S. Gao, Green Chem., 2015, 17, 831-836.

4 Q. Y. Wang, W. C. Tong, C. Ma, T. L. Zhang and L. Yang, Z. Anorg. Allg. Chem., 2015, 641, 1550-1555.

5 G.-H. Tao, Y. Guo, Y.-H. Joo, B. Twamley and J. n. M. Shreeve, J. Mater. Chem., 2008, 18, 5524-5530.

6 G. Drake, T. Hawkins, A. Brand, L. Hall, M. McKay, A. Vij and I. Ismail, Propellants, Explos., Pyrotech., 2003, 28, 174-180.

7 D. E. Chavez, M. A. Hiskey and R. D. Gilardi, Angew. Chem., Int. Ed., 2000, 112, 1861-1863.

8 R. Wang, H. Xu, Y. Guo, R. Sa and J. n. M. Shreeve, J. Am. Chem. Soc., 2010, 132, 11904-11905.

9 C. B. Aakeröy, K. R. Seddon and M. Leslie, Struct. Chem., 1992, 3, 63-65.

10 J. Zhang and J. n. M. Shreeve, J. Am. Chem. Soc., 2014, 136, 4437-4445. 
11 T. M. Klapötke, P. C. Schmid, S. Schnell and J. Stierstorfer, Chem.-Eur. J., 2015, 21, 9219-9228.

12 T. M. Klapötke, P. Mayer, C. Miró Sabaté, J. M. Welch and N. Wiegand, Inorg. Chem., 2008, 47, 6014-6027.

13 T. M. Klapötke, J. R. Stierstorfer and A. U. Wallek, Chem. Mater., 2008, 20, 4519-4530.

14 T. M. Klapötke and C. M. Sabaté, Dalton Trans., 2009, 18351841.

15 R. P. Singh, R. D. Verma, D. T. Meshri and J. n. M. Shreeve, Angew. Chem., Int. Ed., 2006, 45, 3584-3601.

16 H. Gao and J. n. M. Shreeve, Chem. Rev., 2011, 111, 73777436.

17 Y. Tang, H. Gao, L. A. Mitchell, D. A. Parrish and J. n. M. Shreeve, Angew. Chem., Int. Ed., 2016, 128, 32523255.

18 Y. Guo, G. H. Tao, Z. Zeng, H. Gao, D. A. Parrish and J. n. M. Shreeve, Chem.-Eur. J., 2010, 16, 3753-3762.

19 J.-T. Wu, J.-G. Zhang, X. Yin, Z.-Y. Cheng and C.-X. Xu, New J. Chem., 2015, 39, 5265-5271.

20 C. Bian, M. Zhang, C. Li and Z. Zhou, J. Mater. Chem. A, 2015, 3, 163-169.

21 Y.-T. Gao, L.-M. Zhao, F.-Q. Pang, X.-J. Qi, J.-L. Huang and F.-X. Chen, Chin. Chem. Lett., 2015, 27, 433-436.
22 L. Liang, K. Wang, C. Bian, L. Ling and Z. Zhou, Chem.-Eur. J., 2013, 19, 14902-14910.

23 T. M. Klapötke and C. M. Sabaté, Chem. Mater., 2008, 20, 3629-3637.

24 O. Bolton and A. J. Matzger, Angew. Chem., Int. Ed., 2011, 50, 8960-8963.

25 J. Zhang, Q. Zhang, T. T. Vo, D. A. Parris and J. M. Shreeve, J. Am. Chem. Soc., 2015, 137, 1697-1704.

26 T. B. Brill and K. J. James, Chem. Rev., 1993, 93, 2667-2692.

27 H. E. Kissinger, Anal. Chem., 1957, 29, 1702-1706.

28 T. Ozawa, Bull. Chem. Soc. Jpn., 1965, 38, 1881-1886.

29 C. D. Doyle, J. Appl. Polym. Sci., 1961, 5, 285-292.

30 Y. Zhang, Y. Guo, Y. H. Joo, D. A. Parrish and J. n. M. Shreeve, Chem.-Eur. J., 2010, 16, 10778-10784.

31 X. Y. Liu, Q. Yang, Z. Y. Su, S. P. Chen, G. Xie, Q. Wei and S. L. Gao, RSC Adv., 2014, 4, 16087-16093.

32 T. M. Klapötke and C. M. Sabaté, New J. Chem., 2009, 33, 1605-1617.

33 R. Meyer, J. Köhler and A. Homburg, Explosives. Sixth Edition, Wiley VCH Verlag GmbH \& Co. KGaA, Weinheim, 2007.

34 S. Li, Y. Wang, C. Qi, X. Zhao, J. Zhang, S. Zhang and S. Pang, Angew. Chem., Int. Ed., 2013, 52, 14031-14035.

35 M. J. Kamlet and S. Jacobs, J. Chem. Phys., 2003, 48, 23-35. 